\title{
The Influence of Propan-1-Ol on Performance of Alumina-Silica Catalyst over Ethanol Dehydration
}

\author{
Sasiradee Jantasee, Prajak Kanya, Wasuwat Ngoksilapa, and Bunjerd Jongsomjit
}

\begin{abstract}
This research investigated the effect of propan-1-ol on a performance of ethanol dehydration by using an alumina-silica composite $\left(\mathrm{Al}_{2} \mathrm{O}_{3}-\mathrm{SiO}_{2}\right)$ catalyst. It was compared the results to a $\mathrm{H}$-Beta zeolite catalyst. Alumina-silica composite catalyst was prepared in the ratio of 60:40 by precipitation method. The catalysts were characterized using various techniques. The catalysts were tested catalytic activity over the dehydration of ethanol mixed with propan-1-ol at 1 atm of total pressure and the temperature range between 200 to $400{ }^{\circ} \mathrm{C}$. The results show that propan-1-ol decreased ethanol conversion and ethylene yield of the $\mathrm{Al}_{2} \mathrm{O}_{3}-\mathrm{SiO}_{2}$ catalyst about $50 \%$ compared to the dehydration of pure ethanol over the same catalyst. Nevertheless, propan-1-ol did not significantly affect the ethylene selectivity of this catalyst. Ethanol to ethylene preferable occurred at high temperature but propan-1-ol to propylene preferable occurred at low temperature.
\end{abstract}

Index Terms-Ethanol dehydration, alumina-silica, zeolite, propan-1-ol.

\section{INTRODUCTION}

Decreasing amount of petroleum feedstocks and problem with greenhouse gases result in high attention to a biomass utilization [1], [2]. Recently, ethanol utilization is an important alternative to produce fuels for motor vehicle, hydrogen, or chemicals such as ethylene, acetaldehyde, and diethyl ether [3]-[6]. This is because ethanol can be produce from renewable sources. Moreover, biomass-derived ethanol can reduce carbon dioxide emissions [1]. The chemicals production from an ethanol can decrease operating temperature and reduce energy consumption compared to the production from petroleum feedstocks. However, the chemicals production from an ethanol should be able to generate as much chemicals as from petroleum feedstocks. Ethanol dehydration is one of the interesting processes which has been widely studied in academia and industry [7]-[9]. Converting ethanol to ethylene or other chemicals can be obtained by catalytic dehydration using solid acid catalysts such as alumina, zeolite, silica, alumina-silica and mixed metal oxide (such as titanium oxides, cobalt oxides,

Manuscript received February 5, 2017; revised May 20, 2017.

Sasiradee Jantasee, Prajak Kanya, and Wasuwat Ngoksilapa are with the Department of Chemical Engineering, Faculty of Engineering, Rajamangala University of Technology Thanyaburi, Pathum thani 12110, Thailand (e-mail: sasiradee.j@en.rmutt.ac.th,_prajakkanya@hotmail.com, wasuwat.ngks@gmail.com).

Bunjerd Jongsomjit is with Department of Chemical Engineering, Faculty of Engineering, Chulalongkorn University, Bangkok 10330, Thailand (e-mail: bunjerd.j@chula.ac.th). chromium oxide and silver salt of tungstophosphoric acid) [10]-[14].

Many research commonly studied the use of pure ethanol as a feedstock for ethanol dehydration and few research have been investigated on the dehydration of a mixture of water and pure ethanol [8], [10]-[14]. The use of a low purity of ethanol produced by simple flash distillation or a crude bioethanol limiting the purification processes may result in a lower production cost of ethanol dehydration compared to that of a pure ethanol. The dehydration of low purity of ethanol differs from that of pure ethanol because many impurities may affect the catalyst performance. Other alcohols are the most prevailing impurities in crude bioethanol [15], [16]. Propan-1-ol is one of major impurities in crude bioethanol [16].

In this study, propan-1-ol was selected as model to test the performance of catalysts over the dehydration of ethanol containing impurity. The catalytic performance of alumina-silica $\left(\mathrm{Al}_{2} \mathrm{O}_{3}-\mathrm{SiO}_{2}\right)$ and $\mathrm{H}$-Beta zeolite catalysts were compared for the dehydration of ethanol with propan-1-ol as model impurities.

\section{MATERIALS AND EXPERIMENTAL}

\section{A. Materials}

Tetraethyl orthosilicate (TEOS, 98\%), Cetyltrimethylammonium bromide (CTAB, 98\%), Aluminium nitrate (98\%), and ammonia 30\% were purchased from Sigma-Aldrish. H-beta zeolite was supplied from TOSOH which was calcined in air at $700{ }^{\circ} \mathrm{C}$ for $6 \mathrm{~h}$ before use. Ethanol (95\%), 1-propanol (95\%) were used for a reaction test purchased from Merck and Sigma-Aldrich, respectively. Ultra-high purity grade nitrogen was supplied from Linde.

\section{B. Preparation of Alumina-Silica Catalyst}

The desired amount of ammonia solution was mixed with $3.3 \mathrm{~g}$ of cetyltrimethylammonium bromide, and then stirred for $30 \mathrm{~min}$. After that $6.3 \mathrm{~g}$ of tetraethyl orthosilicate was added into the mixture and stirred for $1 \mathrm{~h}$. Then, $16.89 \mathrm{~g}$ of aluminium nitrate was filled into the mixture, and then stirred for $1 \mathrm{~h}$. The resulting product was filtrated, dried at room temperature for $12 \mathrm{~h}$. After that it was dried in an oven at 120 ${ }^{\circ} \mathrm{C}$ for $24 \mathrm{~h}$., and finally calcined in air at $700{ }^{\circ} \mathrm{C}$ for $6 \mathrm{~h}$.

\section{Characterizations of Catalysts}

XRD patterns of all catalysts were measured by using Bruker D8 Advance X-ray diffractometer with $\mathrm{Cu} K_{\alpha}$ radiation $\left(\lambda=1.54056 \AA\right.$ ) over an angle $2 \theta$ range of $10^{\circ}-80^{\circ}$ with a resolution of $0.02^{\circ}$.

The specific surface area, average pore volume, and pore size diameter of the catalysts were determined by 
$\mathrm{N}_{2}$-physisorption using Micromeritics ChemiSorb 2750 Pulse instrument.

Morphology of the catalysts and elemental distribution of a catalyst were investigated by scanning electron microscope (SEM) and energy X-ray spectroscopy (EDX), respectively using Hitashi mode S-3400N

\section{Reaction Test}

Gas-phase ethanol dehydration was performed to determine the catalytic activity and product selectivity of the alumina-silica composite and H-Beta zeolite catalysts. The reaction system is presented in Fig. 1. The reaction was determined using a fixed-bed continuous flow reactor. For the reaction test, quartz wool and the desired amount of catalyst was packed into the middle of a glass tube reactor. The catalyst was pretreated in nitrogen flow $(50 \mathrm{ml} / \mathrm{min})$ at $200{ }^{\circ} \mathrm{C}$ for $1 \mathrm{~h}$. The ethanol or mixture of ethanol and 1 -propanol was vaporized at $120^{\circ} \mathrm{C}$, and then it was injected into the reactor by a single syringe pump. The dehydration reaction was carried out at 1 atm of total pressure and the temperature ranging between $200-400{ }^{\circ} \mathrm{C}$. The light hydrocarbon products were analyzed by gas chromatography technique (Shimadzu GC-14B) with flame ionization detector (FID) using capillary column (DB-5).

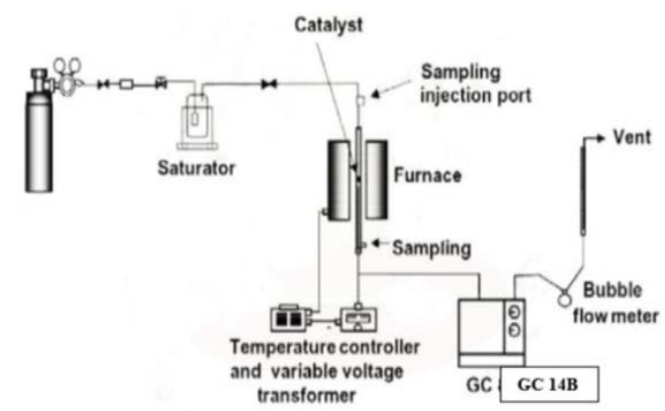

Fig. 1. Flow diagram of dehydration system.

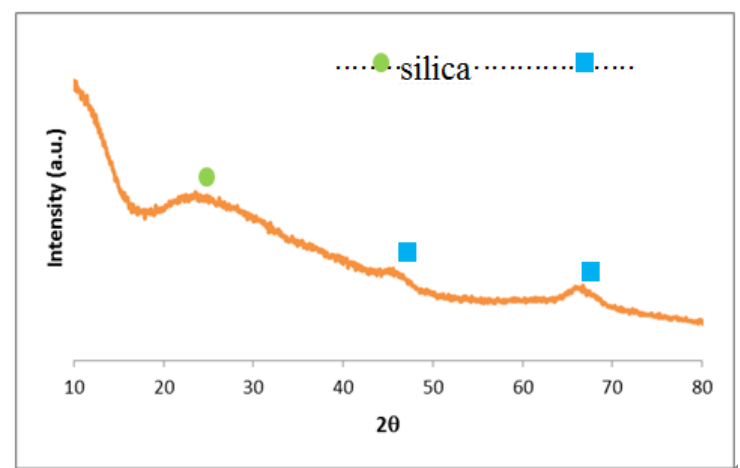

Fig. 2. XRD pattern of the $\mathrm{Al}_{2} \mathrm{O}_{3}-\mathrm{SiO}_{2}$ catalyst.

\section{RESUlts AND DisCUSSION}

\section{A. Characteristics of Catalysts}

Several techniques were performed to characterize the $\mathrm{H}$-Beta zeolite and $\mathrm{Al}_{2} \mathrm{O}_{3}-\mathrm{SiO}_{2}$ catalysts. The XRD pattern of the $\mathrm{Al}_{2} \mathrm{O}_{3}-\mathrm{SiO}_{2}$ catalyst is shown in Fig. 2. The $\mathrm{Al}_{2} \mathrm{O}_{3}-\mathrm{SiO}_{2}$ catalyst exhibited XRD pattern showing the broad peaks between $21-24^{\circ}$ as seen typically for the amorphous structure of silica. Moreover, XRD pattern of this catalyst was appeared the sharp peak around $45^{\circ}$ and $67^{\circ}$ indicating the presence of $\gamma-\mathrm{Al}_{2} \mathrm{O}_{3}$ crystallite [17]. It can confirm that there was alumina and silica in the synthesized $\mathrm{Al}_{2} \mathrm{O}_{3}-\mathrm{SiO}_{2}$ catalyst.

The textural properties characterized by $\mathrm{N}_{2}$ physisorption including surface area and average pore size diameter of the catalysts are shown in Table I. It showed that surface area of the H-beta zeolite catalyst was 2 times higher than that of the $\mathrm{Al}_{2} \mathrm{O}_{3}-\mathrm{SiO}_{2}$ catalyst. On the other hand, the $\mathrm{Al}_{2} \mathrm{O}_{3}-\mathrm{SiO}_{2}$ catalyst indicated larger average pore size diameter than that of the H-beta zeolite catalyst.

TABLE I: TEXTURAL CHARACTERIZATION OF THE CATALYSTS.

\begin{tabular}{lcc}
\hline \hline Catalysts & $\begin{array}{c}\text { BET surface area } \\
\left(\mathrm{m}^{2} / \mathrm{g}\right)\end{array}$ & $\begin{array}{c}\text { Average pore diameter } \\
(\mathrm{nm})\end{array}$ \\
\hline $\mathrm{Al}_{2} \mathrm{O}_{3}-\mathrm{SiO}_{2}$ & 276 & 5.6 \\
$\mathrm{H}-$ Beta zeolite & 522 & 2.2 \\
\hline \hline
\end{tabular}
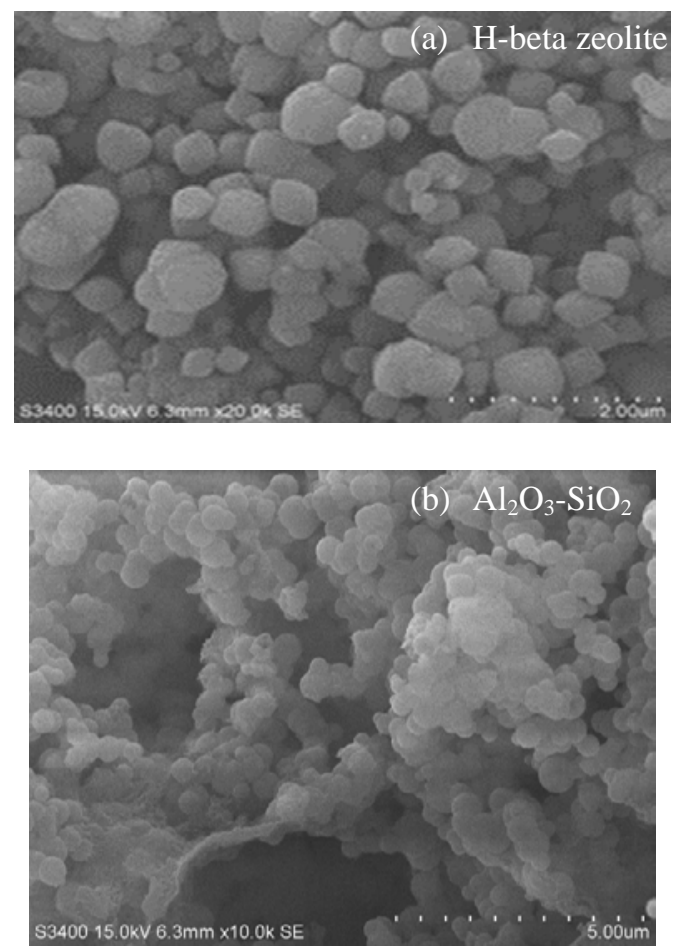

Fig. 3. SEM photographs of (a) H-beta zeolite and (b) $\mathrm{Al}_{2} \mathrm{O}_{3}-\mathrm{SiO}_{2}$ catalysts
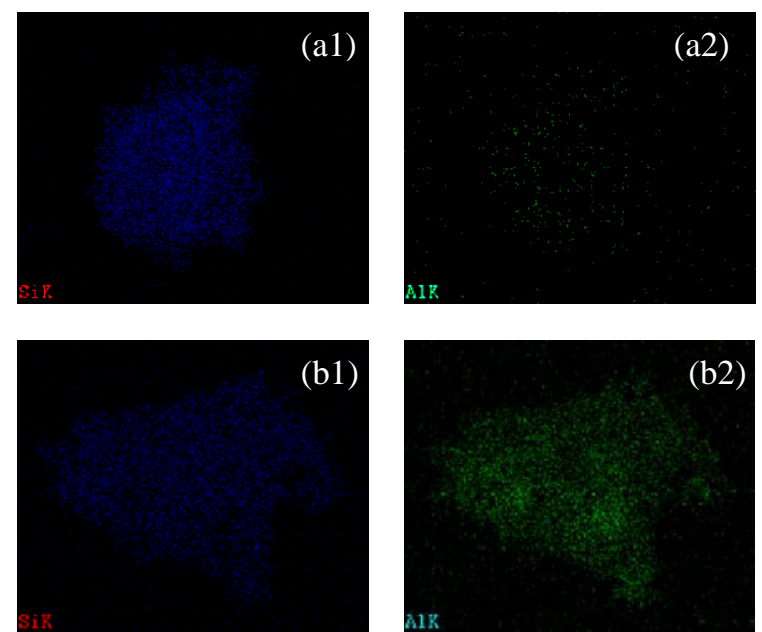

Fig. 4. The typical EDX mapping of (a1) Si (a2) Al distribution on H-beta zeolite catalyst, and (b1) $\mathrm{Si}$ (b2) Al distribution on $\mathrm{Al}_{2} \mathrm{O}_{3}-\mathrm{SiO}_{2}$ catalyst.

The elemental distribution on the catalysts were determined using EDX mapping as shown in Fig. 4. The distribution of $\mathrm{Al}$ and $\mathrm{Si}$ was measured. For the H-Beta zeolite catalyst, the density of Si was strongly measured but the density of $\mathrm{Al}$ was slightly observed. It revealed that $\mathrm{Si}$ is a 
major component of the $\mathrm{H}$-Beta zeolite catalyst. For the $\mathrm{Al}_{2} \mathrm{O}_{3}-\mathrm{SiO}_{2}$ catalyst, $\mathrm{Al}$ and $\mathrm{Si}$ component had the strongly densities on the catalyst surface since both components are the main components of the $\mathrm{Al}_{2} \mathrm{O}_{3}-\mathrm{SiO}_{2}$ catalyst. Moreover, a good distribution of $\mathrm{Al}$ and $\mathrm{Si}$ on the surface of the $\mathrm{Al}_{2} \mathrm{O}_{3}-\mathrm{SiO}_{2}$ catalyst was also observed.

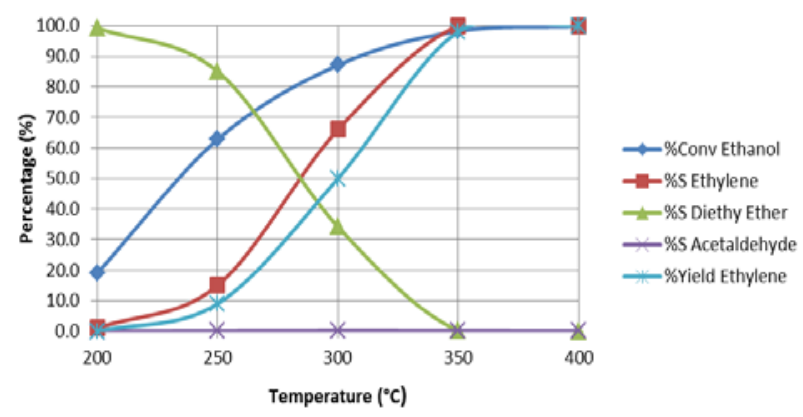

Fig. 5. The results from dehydration of ethanol over H-beta zeolite catalyst.

\section{B. Reaction Test}

The catalytic activities of the H-beta zeolite and the $\mathrm{Al}_{2} \mathrm{O}_{3}-\mathrm{SiO}_{2}$ catalysts were investigated over the dehydration of pure ethanol and mixture of ethanol with propan-1-ol as an impurity. Ethanol dehydration was carried out in temperature ranging between 200 to $400{ }^{\circ} \mathrm{C}$ and atmospheric pressure. For the $\mathrm{H}$-beta zeolite and the $\mathrm{Al}_{2} \mathrm{O}_{3}-\mathrm{SiO}_{2}$ catalysts, ethanol conversions increased with increasing the reaction temperature as seen in Fig. 5 and Fig. 6, respectively. Diethyl ether was a main product when the reaction temperature was lower than $250{ }^{\circ} \mathrm{C}$. Amount of diethyl ether decreased with increasing reaction temperature. On the other hand, ethylene was a major product when the reaction temperature was over $270{ }^{\circ} \mathrm{C}$ and $290{ }^{\circ} \mathrm{C}$ for the $\mathrm{H}$-beta zeolite and the $\mathrm{Al}_{2} \mathrm{O}_{3}-\mathrm{SiO}_{2}$ catalysts, respectively. Thus, selectivity of diethyl ether decreased but selectivity of ethylene increased with increasing the temperature of ethanol dehydration reaction. It can confirm that the reaction temperature is one of significant factors effecting on the ethanol conversion and product selectivity.

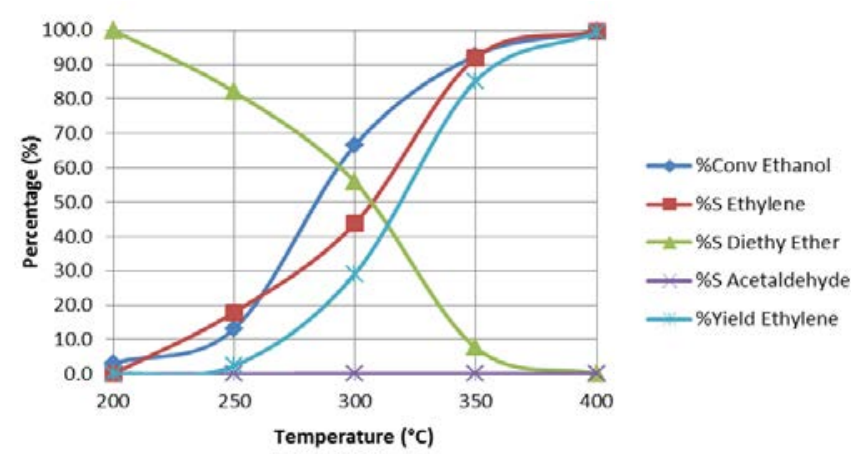

Fig. 6. The results from dehydration of ethanol over $\mathrm{Al}_{2} \mathrm{O}_{3}-\mathrm{SiO}_{2}$ catalyst.

For comparative performance of the H-beta zeolite and the $\mathrm{Al}_{2} \mathrm{O}_{3}-\mathrm{SiO}_{2}$ catalysts over the dehydration of pure ethanol, the H-beta zeolite catalyst exhibited higher conversion of ethanol at all reaction temperatures as seen in Fig. 5 and Fig. 6. Ethanol conversion of the $\mathrm{H}$-beta zeolite reached about $100 \%$ at lower temperature $\left(\sim 350{ }^{\circ} \mathrm{C}\right)$ than that of the $\mathrm{Al}_{2} \mathrm{O}_{3}-\mathrm{SiO}_{2}$ $\left(\sim 400^{\circ} \mathrm{C}\right)$. This may be because the H-beta zeolite had larger amount of weak acid site (0.84 $\mathrm{mmol} \mathrm{NH}_{3} / \mathrm{g}$ catalyst) [18] than the $\mathrm{Al}_{2} \mathrm{O}_{3}-\mathrm{SiO}_{2}$ (0.57 mmol $\mathrm{NH}_{3} / \mathrm{g}$ catalyst) [19]. Normally, weak acid site is identified as a Brønsted acid site which is preferred for ethanol dehydration [20].

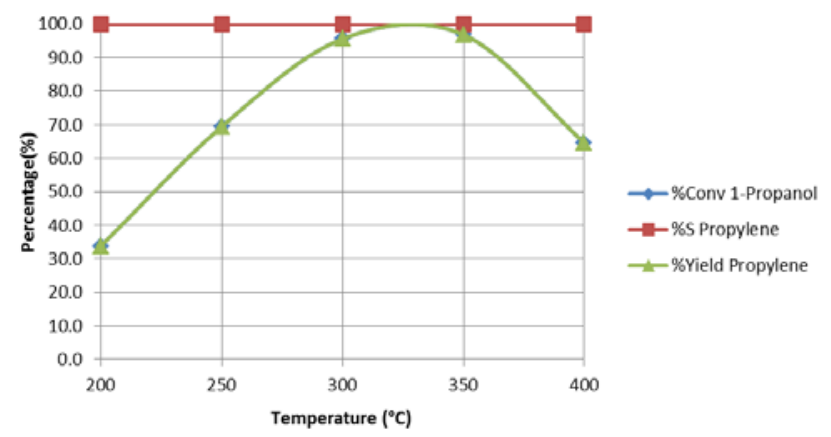

Fig. 7. The results from dehydration of propan-1-ol over H-beta zeolite catalyst.

The dehydration of ethanol mixed with propan-1-ol was performed in order to investigate the effect of propan-1-ol impurity on the catalytic activity and product distribution of the $\mathrm{H}$-beta zeolite and the $\mathrm{Al}_{2} \mathrm{O}_{3}-\mathrm{SiO}_{2}$ catalysts. Ethanol and propan-1-ol were mixed at a ratio of $96: 4 \% \mathrm{v} / \mathrm{v}$, and the mixture was used as a reactant for the dehydration reaction instead of a pure ethanol.

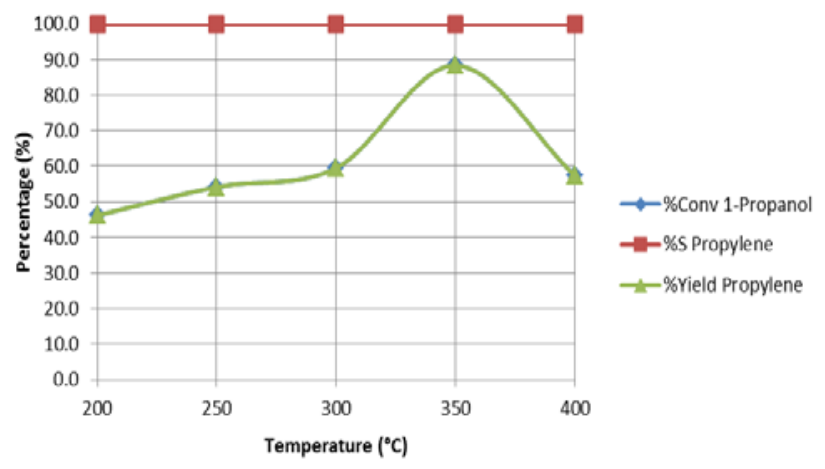

Fig. 8. The results from dehydration of propan-1-ol over $\mathrm{Al}_{2} \mathrm{O}_{3}-\mathrm{SiO}_{2}$ catalyst.

Conversion and yield of ethanol and propan-1-ol, as well as products selectivity of the $\mathrm{H}$-beta zeolite and the $\mathrm{Al}_{2} \mathrm{O}_{3}-\mathrm{SiO}_{2}$ catalysts are presented in Fig. 9 and Fig. 10, respectively. The H-beta zeolite catalyst revealed the highest ethanol conversion of $100 \%$ at $400{ }^{\circ} \mathrm{C}$ and the highest ethanol conversion of the $\mathrm{Al}_{2} \mathrm{O}_{3}-\mathrm{SiO}_{2}$ catalyst was about $49 \%$ at the same temperature. This is because the $\mathrm{H}$-beta zeolite catalyst has higher amount of Brønsted acid site, which is preferred for ethanol dehydration, than the $\mathrm{Al}_{2} \mathrm{O}_{3}-\mathrm{SiO}_{2}$ catalyst [18]-[20]. At $200{ }^{\circ} \mathrm{C}$, it can be observed that both catalysts presented the highest selectivity of propylene. The $\mathrm{Al}_{2} \mathrm{O}_{3}-\mathrm{SiO}_{2}$ catalyst exhibited higher propylene selectivity than the H-beta zeolite catalyst between $200-300{ }^{\circ} \mathrm{C}$. Propylene selectivity decreased with raising the reaction temperature conversely the ethylene selectivity. However, for the dehydration of ethanol mixed with propan-1-ol over the H-beta zeolite catalyst, the ethylene selectivity was reduced approximately 2 times compared to the dehydration of pure ethanol. In case of the $\mathrm{Al}_{2} \mathrm{O}_{3}-\mathrm{SiO}_{2}$ catalyst in the dehydration of ethanol mixed with propan-1-ol, ethylene selectivity was still reached $99 \%$ at $400{ }^{\circ} \mathrm{C}$. This is similar to the result of 
pure ethanol. The H-beta zeolite catalyst presented slightly higher ethylene yield ( 55\%) than the $\mathrm{Al}_{2} \mathrm{O}_{3}-\mathrm{SiO}_{2}$ catalyst ( 48\%).

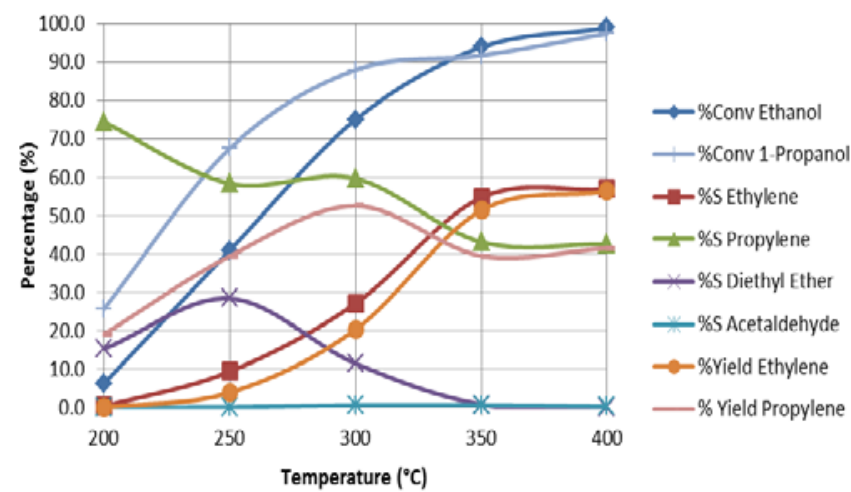

Fig. 9. The results from dehydration of ethanol mixed with propan-1-ol over H-beta zeolite catalyst.

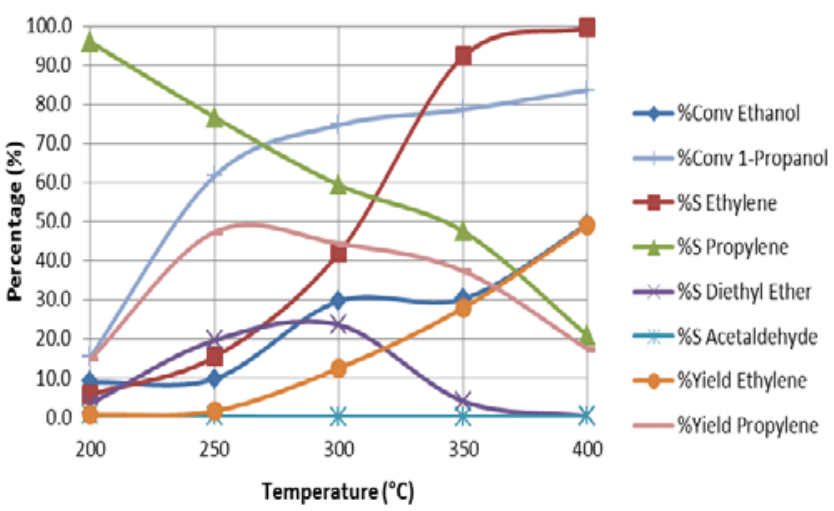

Fig. 10. The results from dehydration of ethanol mixed with propan-1-ol over $\mathrm{Al}_{2} \mathrm{O}_{3}-\mathrm{SiO}_{2}$ catalyst.

\section{CONCLUSION}

The dehydration of ethanol mixed with propan-1-ol as an impurity over the $\mathrm{Al}_{2} \mathrm{O}_{3}-\mathrm{SiO}_{2}$ catalysts was investigated and compared the results to the $\mathrm{H}$-beta zeolite catalyst. For the $\mathrm{Al}_{2} \mathrm{O}_{3}-\mathrm{SiO}_{2}$ catalyst, propan-1-ol influenced the ethanol conversion and ethylene yield. They were decreased about 2 times compared to the results of the dehydration of pure ethanol. However, ethylene selectivity of this catalyst for the dehydration of ethanol mixed with propan-1-ol was similar to that of pure ethanol. For H-beta zeolite catalyst, propanol affected the ethanol conversion, ethylene yield, and ethylene selectivity. Ethanol conversion could be achieved 99\% but it must be performed at higher temperature than the use of pure ethanol. Ethylene yield and ethylene selectivity were about $45 \%$ decreased from the dehydration of pure ethanol. Moreover, propan-1-ol to propylene preferable occurred at low temperature but ethanol to ethylene preferable took place at high temperature.

\section{ACKNOWLEDGMENT}

The authors thank Grant for International Research Integration: Chula Research Scholar, Ratchadaphiseksomphot Endowment Fund for financial support of this project. The authors also extend the thankful for Center of Excellence on Catalysis and Catalytic Reaction Engineering, Department of Chemical Engineering, Faculty of Engineering, Chulalongkorn University for instrumental support.

\section{REFERENCES}

[1] T. Bridgwater, "Review: Biomass for energy,” J. Sci. Food Agric., vol. 86, pp. 1755-1768, 2006.

[2] G.W. Huber, S. Ibora, and A. Corma, "Synthesis of transportation fuels from biomass: Chemistry, catalysts, and engineering,” Chem. Rev., vol. 106, pp. 4044-4098, 2006.

[3] R. K. Niven, "Ethanol in gasoline: Environmental impacts and sustainability review article," Renew Sustainable Energy Rev., vol. 9, pp. 3496-3502, 2005.

[4] Y. Gucbilmez, T. Dogu, and S. Balci, "Ethylene and acetaldehyde production by selective oxidation of ethanol using mesoporous V-MCM-41 catalysts,” Ind. Eng. Chem. Res., vol. 45, pp. 3496-3502, 2006.

[5] A. Haryanto, S. Fernando, N. Murali, and S. Adhikari, "Current status of hydrogen production techniques by steam reforming of ethanol: A review,” Energy Fuels, vol. 19, pp. 2098-2106, 2005.

[6] T. Mallat and A. Baiker, "Oxidation of Alcohols with molecular oxygen on solid catalysts,” Chem. Rev., vol. 104, pp. 3037-3058, 2004.

[7] K. Ramesh, L. M. Hui, Y. F. Han, and A. Borgna, "Structure and reactivity of phosphorous modified H-ZSM-5 catalysts for ethanol dehydration," Cat comm., vol. 10, pp. 567-571, 2009.

[8] L. P. Wu, X. J. Li, Z. H. Yuan, and Y. Chen, "The fabrication of $\mathrm{TiO}_{2}$-supported zeolite with core/shell heterostructure for ethanol dehydration to ethylene," Cat comm., vol. 11, pp. 67-70, 2009.

[9] M. Mokhtar, S. N. Basahel, and T. T. Ali, "Ethanol to hydrocarbons using silver substituted polyoxometalates: Physicochemical and catalytic study,” J. Ind. Eng. Chem., vol. 20, pp. 46-53, 2014.

[10] T. Zaki, L. H. Proietti, A. Lagazzo, and G. Busca, "Dehydration of ethanol over zeolites, silica alumina and alumina: Lewis acidity, Brønsted acidity and confinement effects,” Appl. Catal. A-Gen., vol. 493, pp. 77-89, 2015.

[11] T. Zaki, "Catalytic dehydration of ethanol using transition metal oxide catalysts,” J. Colloid Interface Sci., vol. 284, pp. 606-613, 2005

[12] L. Matachowski, M. Zimowska, D. Mucha, and T. Machej, "Ecofriendly production of ethylene by dehydration of ethanol over $\mathrm{Ag}_{3} \mathrm{PW}_{12} \mathrm{O}_{40}$ salt in nitrogen and air atmospheres," Appl. Catal. B-Environ, vol. 123-124, pp. 448-456, 2012.

[13] T. K. Phung and G. Busca, "Ethanol dehydration on silica-aluminas: Active sites and ethylene/diethyl ether selectivities," Cat Comm., vol. 68, pp. 110-115, 2015.

[14] T. K. Phunga, R. Radikapratama, G. Garbarino, A. Lagazzo, P. Riani, and G. Busca, "Tuning of product selectivity in the conversion of ethanol to hydrocarbons over H-ZSM-5 based zeolite catalysts," Fuel Process Technol., vol. 137, pp. 290-297, 2015.

[15] L.V. Anthony, G. Anthony, B. Nicolas, E. Florence, and D. Daniel "Hydrogen production from raw bioethanol over $\mathrm{Rh} / \mathrm{MgAl}_{2} \mathrm{O}_{4}$ catalyst Impact of impurities: Heavy alcohol, aldehyde, ester, acid and amine," Catal. Today, vol. 138, pp. 169-174, 2008.

[16] L. V. Anthony, G. Anthony, B. Nicolas, D. Daniel, and E. Florence, "Effect of higher alcohols on the performances of a $1 \% \mathrm{Rh} /$ $\mathrm{MgAl}_{2} \mathrm{O}_{4} / \mathrm{Al}_{2} \mathrm{O}_{3}$ catalyst for hydrogen production by crude bioethanol steam reforming,” Int. J. Hydrogen Energy, vol. 36, pp. 311-318, 2011

[17] F. F. Madeira, N.S. Gnep, P. Magnoux, S. Maury, and N. Cadran, "Ethanol transformation over HFAU, HBEA and HMFI zeolites presenting similar Brønsted acidity,” Appl. Catal. A-Gen., vol. 367, pp. 39-46, 2009

[18] K. Tanutporn, "Dehydration reaction of ethanol over beta zeolite catalyst,” M.S. dissertation, Dept. Chem. Eng., Chulalongkorn Univ., Bangkok, Thailand, 2015.

[19] M. Auemporn, "Production of diethylether by catalytic dehydration of ethanol over hydroxyapatite/alumina-silica catalysts," M.S. dissertation, Dept. Chem. Eng., Chulalongkorn Univ., Bangkok, Thailand, 2015.

[20] T. Chanchuey, C. Autthanit, and B. Jongsomjit, "Effect of Mo-doped mesoporous Al-SSP catalysts for the catalytic dehydration of ethanol to ethylene,” J. Chem., pp. 1-8, 2016.

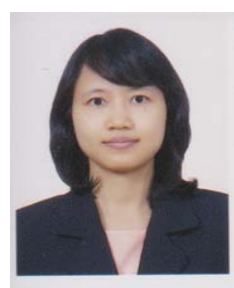

Sasiradee Jantasee was born on May 20, 1987 in Bangkok, Thailand. She is a lecturer in the Department of Chemical Engineering at Rajamangala University of Technology Thanyaburi. She received her doctoral degree in chemical engineering from Chulalongkorn University. She was given the Royal Golden Jubilee (RGJ)-PhD scholarship supported by the Thailand Research Fund for her doctoral degree. 
She obtained her bachelor's degree in chemical engineering from King Mongkut's University of Technology Thonburi.

During her doctoral study, she was an exchange researcher for a year in the Department of Applied Chemistry, Graduate School of Engineering, Hiroshima University, Japan in the field of heterogeneous catalyst for olefins polymerization. She worked as a postdoctoral fellow in Graz University of Technology, Austria during April to September 2016 under Ernst Mach Weltweit TSOA scholarship. Her research field was process intensification in biorefinery for carboxylic acid isolation. Her research interests are currently heterogeneous catalysts, olefins polymerization, ethanol dehydration, ethanol dehydrogenation, pyrolysis of plastic waste, and purification processes.

Dr. Jantasee has published about 10 research articles in international journal and conference such as Journal of Polymer Science Part A: Polymer Chemistry, European Polymer, and Polymer Bulletin.

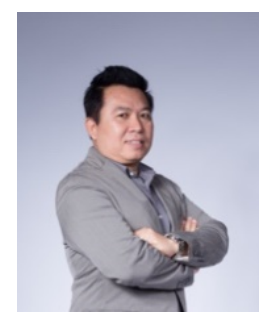

Bunjerd Jongsomjit obtained his $\mathrm{PhD}$ in chemical engineering from University of Pittsburgh, USA, in 2002. He is currently a professor at the Department of Chemical Engineering, Faculty of Engineering, Chulalongkorn University. Professor Jongsomjit is in the research group of Center of Excellence on Catalysis and Catalytic Reaction Engineering. His current research interests are heterogeneous catalysis, kinetics, adsorption, catalyst characterization, steady-state isotopic transient kinetics, catalyst deactivation, CO hydrogenation, natural gas conversion, and advanced catalysts for olefin polymerization.

Professor Jongsomjit has published over 100 research articles in international journal such as Catalysis Communications, Polymer, Powder Technology, Journal of Molecular Catalysis A: Chemical, Applied Surface Science, Journal of Catalysis, and Catalyst today. 